\title{
Critical analysis of the concept of adult attention-deficit hyperactivity disorder
}

\author{
Joanna Moncrieff, ${ }^{1}$ Sami Timimi ${ }^{2}$
}

The Psychiatrist (2011), 35, 334-338, doi: 10.1192/pb.bp.110.033423

${ }^{1}$ University College London;

${ }^{2}$ Lincolnshire Partnership NHS

Foundation Trust

Correspondence to Joanna Moncrieff (j.moncrieff@ucl.ac.uk)

First received 10 Nov 2010, final revision 20 Apr 2011, accepted 10 Jun 2011

\begin{abstract}
Summary We question whether adult attention-deficit hyperactivity disorder $(A D H D)$ represents a discrete condition that is distinguishable from ordinary behaviour and other psychiatric disorders, and whether it is related to the childhood disorder, since adult and childhood ADHD are said to be characterised by a different range of symptoms. Although studies of stimulant drugs find marginal short-term effects, which can be explained by their known psychoactive properties, there is little evidence that there are any sustained long-term benefits of drug therapy. We suggest that adult ADHD represents one of the latest attempts to medicalise ordinary human difficulties, and that its popularity is partly dependent on marketing and the reinforcing effects of stimulants.
\end{abstract}

Declaration of interest Both authors are members of the Critical Psychiatry Network.
In recent years attention-deficit hyperactivity disorder (ADHD) has been diagnosed with increasing frequency in adults as well as children, including increasing numbers of adults who were never diagnosed as children. Current estimates are that between 5 and $9 \%$ of the adult population of high-income countries may have the condition. ${ }^{1,2}$ The phenomenon of adult ADHD started to emerge in the USA during the 1990s, propelled by the activities of patient advocacy groups, the media and professionals. ${ }^{3}$ Over the past decade, there has been increasing academic interest (Fig. 1). The condition is now endorsed by the UK National Institute for Health and Clinical Excellence (NICE) ${ }^{4}$ and will be explicitly included in the forthcoming revision of the American Psychiatric Association's Diagnostic and Statistical Manual of Mental Disorders. ${ }^{5}$

Advocates of the concept of adult ADHD argue that the condition can be reliably defined and diagnosed, that it is distinguishable from other conditions, that it predicts significant adverse outcomes, responds well to stimulant drugs and should be diagnosed more frequently., Moreover, in contrast to previous practice, many experts are recommending that drug treatment of children diagnosed with ADHD should commonly be continued into adulthood. ${ }^{7,8}$ On the other hand, critics have suggested that adult ADHD can be seen as the 'medicalisation of underperformance,, 3,9 and there has also been concern about the widespread diversion and illicit use of prescription stimulants. ${ }^{10}$ It is possible that drugs of misuse have not been so easily obtainable on prescription since the widespread prescription of benzodiazepines in the 1980s. Despite these issues, there has been no detailed analysis of the validity of the condition or the drivers behind its recent ascendance.

\section{The role of the pharmaceutical industry}

Over the past decade, there has been a substantial increase in the use and costs of stimulants and other drugs aimed at treating ADHD. In England, overall prescriptions for stimulants and atomoxetine (which is claimed to be a non-stimulant, but has some stimulant-like side-effects) increased by $259 \%$ between 1998 and 2009, with adjusted costs increasing almost ten times. ${ }^{11}$ The increase has been most marked in older children and adults. ${ }^{7}$ In the USA, prescriptions for stimulants to adults doubled between 2000 and $2005 .^{12}$

The past decade has also seen pharmaceutical marketing companies identify adult ADHD as an 'expanding and lucrative market'. ${ }^{13}$ In 2002, Eli Lilly ran advertising campaigns for Strattera (atomoxetine), which were criticised by the US Food and Drug Administration for expanding the indications for the drug, overstating its benefits and understating risks. ${ }^{14,15}$ One campaign included television advertisements featuring people experiencing such everyday occurrences as forgetting car keys and being distracted by a shop window. ${ }^{14}$ Encouraging selfdiagnosis has been a prominent part of adult ADHD marketing campaigns, with company-run and other commercially sponsored websites featuring questionnaires that people can self-administer to see whether they have the condition, and encouraging people to ask their health professionals about drug treatment. Company material also reinforces the notion that adult ADHD is a brainbased disease state, 'a real, and treatable, medical condition'. ${ }^{16}$

Much promotion is currently aimed at women, and data from the USA show that the use of prescription stimulants by adults has increased most among women. ${ }^{12}$ 


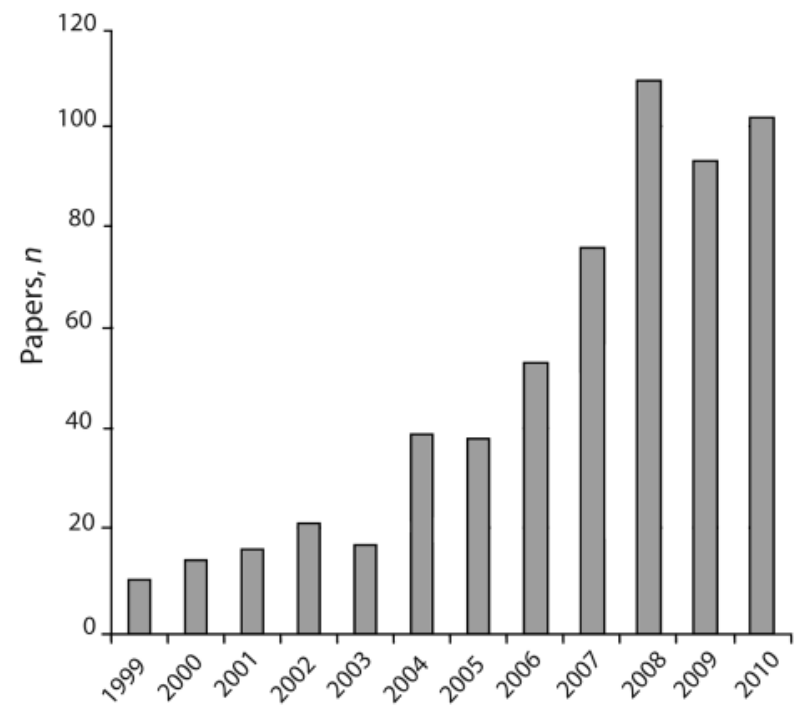

Fig 1 Number of papers published on adult attention-deficit hyperactivity disorder (ADHD) in Medline since 1999 (retrieved using search terms 'adult ADHD', 'adult attention deficit disorder' and 'adult attention-deficit hyperactivity disorder').

The Health.com website, which offers 'smart, strategic advertising opportunities ${ }^{, 17}$ to its clients, describes adult ADHD to women as 'a neurobehavioural condition marked by poor memory, the inability to concentrate on important tasks, and tendency to fidget and daydream, among other symptoms' and encourages women to consider the diagnosis by describing how symptoms may be 'more subtle and easily missed' in women. ${ }^{18}$ The commercially sponsored ADDitude Magazine's website (www.additudemag.com; ADD, attention deficit disorder) also worries that 'too often ... women and girls [with ADD] go undiagnosed and untreated' and carries an article to help them 'learn how to recognise symptoms and get help. ${ }^{19}$

In 2008, it was revealed by a senatorial investigation in the USA that Professor Joseph Biederman and some other researchers based at Harvard University, who had promoted the concept of adult ADHD and conducted much of the research including drug trials, had failed to disclose all the income they had received from pharmaceutical companies. $^{20}$ They subsequently admitted to receiving millions of dollars over several years collectively, and data obtained from the companies involved suggested the figures could be higher still. ${ }^{20}$

\section{The diagnosis of adult ADHD}

The reason that adult ADHD is so appealing to drug companies can be readily deduced from official symptom lists and proposed diagnostic criteria, which consist of multiple experiences and behaviours that are practically universal (Box 1). The draft fifth revision of the Diagnostic and Statistical Manual of Mental Disorders ${ }^{5}$ provides examples of behaviour that might qualify as symptoms, including failing to pay attention to detail, difficulty 'remaining focused during lectures, conversations or reading lengthy writings', showing reluctance to engage in
Box 1 National Health Service criteria for adult attention-deficit hyperactivity disorder

- Carelessness and lack of attention to detail

- Continually starting new tasks before finishing old ones

- Poor organisational skills

- Inability to focus or prioritise

- Continually losing or misplacing things

- Forgetfulness

- Restlessness and edginess

- Difficulty keeping quiet and speaking out of turn

- Blurting responses, and poor social timing when talking to others

- Often interrupting others

- Mood swings

- Irritability and a quick temper

- Inability to deal with stress

- Extreme impatience

- Taking risks in activities, often with little or no regard for personal safety or the safety of others

Source: NHS Choices (www.nhs.uk/conditions/attention-deficithyperactivity-disorder/pages/symptoms.aspx)

'homework . . . preparing reports, or reviewing lengthy papers', frequently losing objects such as 'keys, paperwork, eyeglasses or mobile telephones', 'starting tasks without adequate preparation or avoiding reading or listening to instructions', and 'impulsively buying items, suddenly quitting a job, or breaking up with a friend'.

Although DSM-5 proposals and other criteria specify that symptoms must impair 'social, academic, or occupational functioning, 5 it is difficult to think of circumstances in which someone seeking help would not fulfil, or believe they fulfil, these criteria. There is also no empirical or logical basis on which such diverse phenomena should be grouped together.

The concept of adult ADHD derives its face validity from its supposed similarity with the childhood condition. There have been many challenges to the validity of the childhood disorder, ${ }^{21-23}$ but even if these are set aside, it is not clear that the two diagnoses are related, since there appears to be a consensus that people with adult ADHD have a different spectrum of symptoms from children, and it is purely on the basis of symptoms that the two disorders are identified or diagnosed. Suggested features of adult ADHD include numerous aspects of mental functioning and behaviour that are not even examined in children, including lability of mood, stress intolerance, anger and risk-taking. Some commonly used assessment scales for adults include whole new domains such as 'problems with self concept'. ${ }^{24}$ Moreover, whereas hyperactivity is considered as one of the core features of the childhood condition, specifications of adult ADHD suggest it is not an essential or even common feature, and some assessment scales exclude hyperactivity altogether. ${ }^{25}$

There is also a pronounced discrepancy in the gender distribution of the childhood and adult conditions. The 
diagnosis of childhood ADHD is strongly associated with being a boy ${ }^{23}$ but adult ADHD in many countries is more commonly diagnosed in women. ${ }^{12}$

The current concept of adult ADHD is also incompatible with the previous view that $\mathrm{ADHD}$ is a developmental disorder, which the majority of children will mature out of as their development catches up. ${ }^{26}$ Follow-up studies and some imaging studies were believed to support this hypothesis, ${ }^{27,28}$ which also explains the preponderance of boys with ADHD, since development in boys, including neurological development, is slower than in girls. It is now claimed, however, that $60 \%$ of children diagnosed with ADHD continue to show symptomatic impairment into adulthood. ${ }^{29}$ Follow-up studies report rates of persistence as widely varying as $4-70 \%$ after age 18, with differences likely to be explained by the criteria used and the nature of the cohort, including comorbidity. ${ }^{29}$ Data on prescribing in the UK, however, found that most young people had stopped taking stimulants by age $21,{ }^{7}$ and although the authors of this paper concluded this was evidence of inappropriate under-treatment, it may also reflect the natural reduction of symptoms with age, consistent with the developmental hypothesis of ADHD.

In any case, since adult ADHD is thought to involve lower levels of the core features of childhood ADHD, is said to be characterised by some symptoms that are not part of the childhood condition, and has a different gender distribution, there seems to be little basis for concluding that they are the same disorder. The NICE guideline endorsed the concept of adult ADHD on the basis of the absence of consistent evidence of a difference from childhood ADHD, rather than any positive evidence of similarity. ${ }^{4}$

The well-documented rates of comorbidity in people diagnosed with adult ADHD also raise questions about viewing adult ADHD as a discrete disorder. In the US National Comorbidity Survey, $38 \%$ of adults diagnosed with ADHD also fulfilled the criteria for a mood disorder, $47 \%$ for an anxiety disorder, $15 \%$ for a substance use disorder and $20 \%$ for intermittent explosive disorder. ${ }^{1}$ Another study found that $87 \%$ of adults diagnosed with ADHD had at least one other psychiatric diagnosis, and $56 \%$ had two. ${ }^{30}$ The NICE guideline on ADHD noted the overlap with various personality disorders, including antisocial, borderline and emotionally unstable personality disorders as well as depression, anxiety and modern conceptions of bipolar and bipolar-spectrum disorder. ${ }^{4}$

Other aspects of the validity of adult ADHD have not been adequately addressed either. It has not been established, for example, that the symptoms reliably cluster together or that they predict specific patterns of impairment and outcome. Although some research suggests that adult ADHD is associated with reduced academic, work and driving performance, ${ }^{31-33}$ this is not surprising since the diagnostic criteria themselves describe various difficulties in functioning. The diagnosis, therefore, appears to be tautological, in that it is defined by behavioural impairments, but is then said to be valid because it predicts other similar functional difficulties. In addition, the research on associated impairments of adult ADHD has not adequately controlled for the impact of the numerous co-occurring conditions and problems.
Evidence from structural and functional brain studies and genetic associations is also cited to support the validity of the diagnosis, ${ }^{34}$ but few of these studies have involved adults, and so far they remain inconclusive. Genetic studies suggest that the heritability of adult ADHD is considerably lower than that of the childhood disorder ${ }^{6}$ and of other psychiatric conditions such as depression. Molecular genetic studies have indentified some potential associations with candidate genes, but many are different from those thought to be associated with childhood ADHD. ${ }^{6}$ As for children, structural brain imaging studies of adults with ADHD have so far yielded inconsistent and contradictory results. $^{35-37}$

\section{Drug treatment}

The strongest claim that adult ADHD has to validity as a discrete, neurobiologically based brain disease is the contention that it responds specifically to stimulant medication. Low-dose stimulants are recognised to produce short-term behavioural alterations, including increased attention and reduced activity in animals and human volunteers (only at higher doses, like those used recreationally, do they start to increase activity), ${ }^{38}$ but the evidence that they have any worthwhile, sustained benefits, or any specific effects in people with ADHD, is weak.

Studies in children show that any beneficial effects are not sustained on long-term follow-up. ${ }^{39}$ No impact on quality of life or academic performance has been consistently demonstrated either and NICE guidelines recommended restricting stimulant use to children with the most severe symptoms, or those in whom other treatments have failed. ${ }^{4}$

In adults, however, NICE recommended stimulants as a first line of treatment, based on three randomised trials, two of which were conducted by Joseph Biederman and colleagues. In contrast, a meta-analysis of a larger group of short-term methylphenidate studies found that there was no significant difference between the drug and placebo in parallel group studies, generally considered to be the superior design, although there was a modest difference in crossover studies. ${ }^{40}$ Results of the meta-analysis were also substantially influenced by studies conducted by the Biederman group, who reported considerably larger effect sizes than other studies. The authors of the meta-analysis also noted several methodological deficiencies of the studies as a whole, including the fact that the integrity of the double blind was only tested in one study, in which all the participants could correctly identify whether they were taking the drug or the placebo. ${ }^{41}$

Two more short-term trials, one conducted by Janssen-Cilag, makers of Concerta (methylphenidate hydrochloride) and one by Biederman and colleagues, found small differences of around 4 points in the 54-point ADHD rating scale between drug-treated and placebotreated individuals. ${ }^{42,43}$

The only longer-term data from a randomised trial ${ }^{44}$ showed no difference between atomoxetine and placebo on the primary outcome measure of work productivity at 6 months, and no difference in overall ADHD-related quality of life. One out of four symptom measures showed a small 
but significant 1.6 point difference between drug and placebo on a 54-point symptom scale, but this is unlikely to be clinically significant. There were no differences on other outcomes, including the Clinical Global Impressions (CGI) scale and the Driving Behaviour Survey scores.

The evidence from randomised trials in adults and children therefore provides little basis for the sort of longterm drug treatment that is now being implemented for adults presenting with ADHD de novo, or for those with a continuation of a childhood presentation.

\section{Discussion}

The analysis presented here suggests that the validity of the diagnosis of adult ADHD is questionable, and that the drug treatments that are meant to improve the symptoms have not clearly demonstrated either efficacy or utility. The concept does not fulfil any conventionally accepted medical criteria of a disorder or a disease, in that it is not easily distinguishable from 'normality', there is a large overlap with other conditions, outcome is heterogeneous and there is little evidence that drug treatment is specific or effective. Moreover, since there is a discrepancy between childhood and adult ADHD in terms of symptoms and gender profile, it seems questionable whether there is any relation between the two conditions.

Although the pharmaceutical industry did not play a large role in the initial emergence of adult ADHD in the 1990s, the explosion of interest over the past decade and the exponential rise in the use of prescription stimulants coincide with the increasing involvement of the pharmaceutical industry. The extent of promotional material aimed at women suggests that companies may be targeting markets previously occupied by other psychotropic drugs, in the same way that pharmaceutical marketing helped transform anxiety into depression in the 1990s to market the new antidepressants. ${ }^{45}$ According to this view, adult ADHD is one of the latest frameworks being offered to women through which to perceive their distress and dissatisfaction. ${ }^{46}$

Aside from the involvement of industry, the rise of managed care in the USA, which favours cheap treatments such as drugs over more expensive treatments such as longterm psychotherapy, is likely to have promoted the diagnosis of adult ADHD over diagnoses such as personality disorder. Adult ADHD may also be more socially acceptable than other psychiatric diagnoses, and hence present a lesser deterrent to entering the sick role. It is also attractive for providing special exemptions from study requirements at colleges and universities. ${ }^{3}$

Moreover, unlike other psychiatric conditions, where treatment involves drugs that are usually experienced as unpleasant, stimulant drugs have a street value and misuse potential, owing to their ability to enhance arousal and produce euphoria. Diversion of prescription stimulants is well documented among American college students, ${ }^{10}$ and evidence suggests that such practices are also present in the UK and Australia. ${ }^{47,48}$ A quick internet search using the phrase 'how to fake ADHD' reveals a small industry devoted to obtaining stimulants, with numerous discussions and articles with advice on to how to do it. ${ }^{49}$ The practice is said to be widespread, ${ }^{50}$ and a study of individuals addicted to amphetamine also found that they were well aware of how to use a diagnosis of adult ADHD to obtain their drug of choice. $^{51}$

Use of stimulant drugs is not without risks, and there is little evidence that they enhance cognitive abilities in any useful way. ${ }^{52}$ Although growth suppression is not a concern in adults, effects on the cardiovascular system are potentially more significant than they are in children. Stimulants are known to increase heart rate and blood pressure, and those with long-term, heavy recreational use are at increased risk of myocardial infarction and stroke. ${ }^{53}$ Physical dependence on stimulants results in withdrawal or 'rebound' reactions, and may complicate attempts to stop drug treatment. Psychological reliance on drug treatment may deter people from making changes that may have a more lasting impact on their problems.

Although the benefits of long-term stimulant treatment remain questionable, we suggest it is premature to start widespread prescribing to adults. Rather than viewing adult ADHD as a medical disorder, it may be better understood as representing the medicalisation of various common difficulties driven, among other factors, by the interests of the pharmaceutical industry and the reinforcing effects of stimulants.

\section{About the authors}

Joanna Moncrieff is a senior lecturer, Department of Mental Health Sciences, University College London, and Sami Timimi is a consultant in child and adolescent psychiatry, Lincolnshire Partnership NHS Foundation Trust, Sleaford, Lincolnshire, UK.

\section{References}

1 Kessler RC, Adler L, Barkley R, Biederman J, Conners CK, Demler O, et al. The prevalence and correlates of adult ADHD in the United States: results from the National Comorbidity Survey Replication. Am J Psychiatry 2006; 163: 716-23.

2 Simon V, Czobor P, Bálint S, Mészáros A, Bitter I. Prevalence and correlates of adult attention-deficit hyperactivity disorder: metaanalysis. Br J Psychiatry 2009; 194: 204-11.

3 Conrad P, Potter D. From hyperactive children to ADHD adults: observations on the expansion of medical categories. Soc Prob 2000; 47: $559-82$

4 National Institute for Health and Clinical Excellence. Attention Deficit Hyperactivity Disorder: Diagnosis and Management of ADHD in Children, Young People and Adults (National Clinical Practice Guideline Number 72). NICE, 2008.

5 American Psychiatric Association. Proposed Revisions to the Diagnostic and Statistical Manual. APA, 2010.

6 Kooij SJ, Bejerot S, Blackwell A, Caci H, Casas-Brugue M, Carpentier PJ et al. European consensus statement on diagnosis and treatment of adult ADHD: The European Network. Adult ADHD. BMC Psychiatry 2010; 10: 67.

7 Wong IC, Asherson P, Bilbow A, Clifford S, Coghill D, DeSoysa R, et al. Cessation of attention deficit hyperactivity disorder drugs in the young (CADDY) - a pharmacoepidemiological and qualitative study. Health Technol Assess 2009; 13: iii-xi, 1-120.

8 Taylor N, Fauset A, Harpin V. Young adults with ADHD: an analysis of their service needs on transfer to adult services. Arch Dis Child 2010; 95: $513-7$.

9 Shaffer D. Attention deficit hyperactivity disorder in adults. Am J Psychiatry 1994; 151: 633-8. 
10 Arria AM, Caldeira KM, O'Grady KE, Vincent KB, Johnson EP, Wish ED. Nonmedical use of prescription stimulants among college students: associations with attention-deficit-hyperactivity disorder and polydrug use. Pharmacotherapy 2008; 28: 156-69.

11 NHS Information Centre. Prescription Cost Analysis, England - 2009. The Information Centre, 2010.

12 Castle L, Aubert RE, Verbrugge RR, Khalid M, Epstein RS. Trends in medication treatment for ADHD. J Atten Disord 2007; 10: 335-42.

13 Lead Discovery. Adult ADHD - Therapeutic Opportunities. Lead Discovery, 2004 (http://www.leaddiscovery.co.uk/reports/813/Adult_ADHD_ Therapeutic_Opportunities).

14 Food and Drug Administration. FDA warning letter RE: NDA 21-411, Strattera (atomoxetine $\mathrm{HCl}$ ). FDA, 2005 (http://pharmcast.com/ WarningLetters/Yr2005/Jun2005/EliLilly0605.htm).

15 Food and Drug Administration. Warning letter RE: NDA 21-411 Strattera (atomoxetine $\mathrm{HCl}$ ). FDA, 2008 (http://www.fda.gov/downloads/ Drugs/GuidanceComplianceregulatorylnformation/Enforcement ActivityFDA/WarningLettersandNotice of ViolationLettersto PharmaceuticalCompanies/ucm054007.pdf).

16 Ortho-McNeil-Janssen Pharmaceuticals. It's a good day to start getting your ADHD/ADD symptoms under control. Concerta, 2010 (http:// www.concerta.net/adult/adult-index.html).

17 Health.com. Advertiser opportunities. Health.com, 2011 (http://www. health.com/health/static/advertise-digital/online_advertisers.html).

18 Renki M. ADHD affects women differently: what to look for, how to fix it. Health, 2000 (http://www.health.com/health/condition-article/ $0,20283301,00 . \mathrm{html})$.

19 Connolly M. ADD women and girls: late diagnosis, little treatment. ADDitude Magazine 2010; August/September (http://www. additudemag.com/adhd/article/1626.html).

20 Harris G, Carey B. Researchers fail to reveal full drug pay. New York Times 2008; 8 June.

21 Breggin P. Talking Back to Ritalin: What Doctors aren't Telling You about Stimulants and ADHD. Perseus Publishing, 2001.

22 Timimi S, Moncrieff J, Jureidini J, Leo J, Cohen D, Whitfield C, et al A critique of the international consensus statement on ADHD. Clin Child Fam Psychol Rev 2004; 7: 59-63.

23 Timimi S. Naughty Boys: Anti-Social Behaviour, ADHD and the Role of Culture. Palgrave Macmillan, 2005.

24 Conners CK, Erhardt D, Sparrow E. Conners' (CAARS) Adult ADHD Rating Scales - Technical Manual. Multi-Health Systems, 1999.

25 Brown TE. Brown Attention-Deficit Disorder Scales (Manual). Psychological Corporation, 1996.

26 Kinsbourne M. Minimal brain dysfunction as a neurodevelopmental lag. Ann NY Acad Sci 1973; 205: 268-73.

27 Hill JC, Schoener EP. Age-dependent decline of attention deficit hyperactivity disorder. Am J Psychiatry 1996; 153: 1143-6.

28 Shaw P, Eckstrand K, Sharp W, Blumenthal J, Lerch JP, Greenstein D, et al. Attention-deficit/hyperactivity disorder is characterized by a delay in cortical maturation. Proc Natl Acad Sci USA 2007; 104: 19649-54.

29 Faraone SV, Biederman J, Mick E. The age-dependent decline of attention deficit hyperactivity disorder: a meta-analysis of follow-up studies. Psychol Med 2006; 36: 159-65.

30 McGough JJ, Smalley SL, McCracken JT, Yang M, Del'Homme M, Lynn $\mathrm{DE}$, et al. Psychiatric comorbidity in adult attention deficit hyperactivity disorder: findings from multiplex families. Am J Psychiatry 2005; 162: $1621-7$.

31 de Graaf R, Kessler RC, Fayyad J, ten Have M, Alonso J, Angermeyer M, et al. The prevalence and effects of adult attention-deficit/hyperactivity disorder (ADHD) on the performance of workers: results from the WHO World Mental Health Survey Initiative. Occup Environ Med 2008; 65: $835-42$.

32 Fried R, Petty CR, Surman CB, Reimer B, Aleardi M, Martin JM, et al. Characterizing impaired driving in adults with attention-deficit/ hyperactivity disorder: a controlled study. J Clin Psychiatry 2006; 67: 567-74.
33 Biederman J, Petty C, Fried R, Fontanella J, Doyle AE, Seidman LJ, et al. Impact of psychometrically defined deficits of executive functioning in adults with attention deficit hyperactivity disorder. Am J Psychiatry 2006; 163: 1730-8.

34 Asherson $P$, Adamou $M$, Bolea $B$, Muller $U$, Morua SD, Pitts $M$, et al. Is ADHD a valid diagnosis in adults? Yes. BMJ 2010; 340: c549.

35 Frodl T, Stauber J, Schaaff N, Koutsouleris N, Scheuerecker J, Ewers M, et al. Amygdala reduction in patients with ADHD compared with major depression and healthy volunteers. Acta Psychiatr Scand 2010; 121: $111-8$.

36 Seidman LJ, Biederman J, Liang L, Valera EM, Monuteaux MC, Brown A, et al. Gray matter alterations in adults with attention-deficit/ hyperactivity disorder identified by voxel based morphometry. Biol Psychiatry 2011; 69: 857-66.

37 Perlov E, Philipsen A, van Elst LT, Ebert D, Henning J, Maier S, et al. Hippocampus and amygdala morphology in adults with attention-deficit hyperactivity disorder. J Psychiatry Neurosci 2008; 33: 509-15.

38 Arnsten AF. Stimulants: therapeutic actions in ADHD. Neuropsychopharmacology 2006; 31: 2376-83.

39 Jensen PS, Arnold LE, Swanson JM, Vitiello B, Abikoff HB, Greenhill LL, et al. 3-year follow-up of the NIMH MTA study. J Am Acad Child Adolesc Psychiatry 2007; 46: 989-1002.

40 Koesters M, Becker T, Kilian R, Fegert JM, Weinmann S. Limits of metaanalysis: methylphenidate in the treatment of adult attention-deficit hyperactivity disorder. J Psychopharmacol 2009; 23: 733-44.

41 Gualtieri CT, Ondrusek MG, Finley C. Attention deficit disorders in adults. Clin Neuropharmacol 1985; 8: 343-56.

42 Medori R, Ramos-Quiroga JA, Casas M, Kooij JJ, Niemela A, Trott GE, et al. A randomized, placebo-controlled trial of three fixed dosages of prolonged-release OROS methylphenidate in adults with attentiondeficit/hyperactivity disorder. Biol Psychiatry 2008; 63: 981-9.

43 Adler LA, Zimmerman B, Starr HL, Silber S, Palumbo J, Orman C, et al. Efficacy and safety of OROS methylphenidate in adults with attentiondeficit/hyperactivity disorder: a randomized, placebo-controlled, double-blind, parallel group, dose-escalation study. J Clin Psychopharmacol 2009; 29: 239-47.

44 Adler A, Spencer TJ, Levine LR, Ramsey JL, Tamura R, Kelsey D, et al. Functional outcomes in the treatment of adults with ADHD. J Atten Disord 2008; 11: 720-7.

45 Healy D. Shaping the intimate: influences on the experience of everyday nerves. Soc Stud Sci 2004; 34: 219-45.

46 Usher J. Women's Madness: Misogyny or Mental Illness? University of Massachusetts Press, 1991.

47 Sumnall HR, Woolfall K, Cole J, Mackridge A, McVeigh J. NICE guidance on ADHD: diversion and abuse of methylphenidate in light of new guidance. BMJ 2008; 337: a2287.

48 Government of Western Australia. Australian Secondary Students Alcohol and Drug Survey 2005, Summary of Western Australia Results (Report No. 37). Statistical Bulletin Number 37, Drug and Alcohol Office, Government of Western Australia, 2007.

49 Magomedov A. Adderal tips: how to convince your shrink you have ADHD/ADD. The Exiled, 2006 (http://exiledonline.com/adderall-tipshow-to-convince-your-shrink-you-have-addadhd/).

50 Gardner A. Some fake ADHD to get meds, special treatment. Medicinenet, 2010 (http://www.medicinenet.com/script/main/ art.asp?articlekey=119239)

51 Schubert S, Hansen S, Dyer K, Rapley M. 'ADHD patient' or 'illicit drug user'? Managing medico-moral membership categories in drug dependence services. Discourse Society 2009; 20: 499-516.

52 Williams SJ, Martin P. Risks and benefits may turn out to be finely balanced. Nature 2009; 457: 532

53 Westover AN, McBride S, Haley RW. Stroke in young adults who abuse amphetamines or cocaine: a population-based study of hospitalized patients. Arch Gen Psychiatry 2007; 64: 495-502. 